\title{
The Effects of Task Repetition on Child EFL Learners' Oral Performance
}

\author{
Bo Sun \\ University College London \\ Andrea Révész \\ University College London
}

\begin{abstract}
While the role of task repetition has received much attention in task-based research, few studies have examined how exact task repetition affects the performance of child second language learners. Also, little is known about the impact of exact task repetition on trade-off effects between linguistic performance areas among child learners. To help fill this gap, we investigated the impact of task repetition on 40 Chinese EFL learners' oral production. The children repeated the same story-telling task three times, and transcripts of their performance were coded for linguistic complexity, accuracy, and fluency. Complexity was expressed in terms of overall complexity and subordination and phrasal complexity. We assessed accuracy with weighted clause ratios and proportion of errors. Fluency was captured by repair and breakdown fluency measures. Wilcoxon signed rank tests revealed positive effects for task repetition on fluency and accuracy. Trade-off effects observed during participants' first performance had decreased by their third retelling. These results support Skehan's (1998) Limited Capacity model and suggest that task repetition is a useful pedagogical tool in instructed child L2 contexts.
\end{abstract}

\section{Résumé}

Alors que le rôle de la répétition des tâches a reçu beaucoup d'attention dans la recherche sur l'apprentissage par tâches, peu d'études ont examiné comment la répétition exacte des tâches affecte la performance des enfants apprenant une L2. De plus, on sait peu sur l'impact de la répétition exacte sur les effets de compensation entre les domaines de performance linguistique chez ces enfants. Pour combler cette lacune, nous avons étudié l'impact de la répétition d'une tâche sur la production orale de 40 apprenants chinois d'anglais L2. Les enfants ont répété la même narration trois fois, et nous avons codé les transcriptions de leurs performances pour la complexité, la précision, et la fluidité linguistiques. La complexité a été exprimée en matière de complexité globale, de subordination, et de complexité phrastique. Nous avons évalué la précision à l'aide de ratios pondérés de propositions et de la proportion d'erreurs. La fluidité a été saisie par des mesures de fluidité de réparation et de rupture. Des tests de rangs signés de Wilcoxon ont révélé des effets positifs de la répétition sur la fluidité et la précision. Les effets de compensation observés lors de la première performance avaient diminué lors de la troisième répétition. Ces résultats appuient le modèle de capacité limitée de Skehan (1998) et suggèrent que la répétition des tâches est un outil pédagogique utile dans les contextes d'enseignement d'une L2 aux enfants. 


\section{The Effects of Task Repetition on Child EFL Learners' Oral Performance}

For the past three decades, pedagogic tasks as a means of facilitating second language development have been the subject of much attention among instructed second language acquisition (SLA) researchers. Pedagogic tasks are defined as classroom activities, which promote meaningful language use to attain a particular non-linguistic outcome, with the holistic goal of facilitating language learning (Samuda \& Bygate, 2008). A principal rationale for integrating tasks into second language (L2) teaching is that, while engaging L2 learners in language use that resembles how the L2 is used in real-life contexts, they provide a platform for a simultaneous focus on meaning and form, which is generally accepted to be a prerequisite to attain advanced L2 communicative ability (e.g., Long \& Robinson, 1998).

Given the putative benefits associated with the use of tasks in L2 teaching, a large amount of task-based research has focused on identifying task characteristics and implementation factors that may maximize L2 development through engaging in task work. Among the many task features explored to date, task repetition is one of the most studied task implementation factors. Task repetition involves "repetitions of the same or slightly altered tasks - whether whole tasks or parts of a task" (Bygate \& Samuda, 2005, p. 43). Task repetition can take various forms, such as repeating the same task type with the same content (exact task repetition) or with different content (procedural task repetition or tasktype repetition). Our focus in this study was the impact of repeating a task type with the same content. Unless stated otherwise, we use the term task repetition to refer to this procedure.

By now, the positive effects of task repetition, exact or procedural, have been confirmed for both adult (e.g., Ahmadian \& Tavakoli, 2011; Bygate, 1996, 2009; Fukuta, 2016; Lambert et al., 2017; Lynch \& Maclean, 2000, 2001; Sheppard \& Ellis, 2018) and child (e.g., Kim \& Tracy-Ventura, 2013; Mackey et al., 2007; Pinter, 2005, 2007a, 2007b; Sample \& Michel, 2014; Thai \& Boers, 2016) populations. However, the precise influence of repeating a task on various linguistic performance areas such as linguistic complexity, accuracy, and fluency (CAF) needs further investigation. Although there is ample evidence suggesting that repeating a task promotes the quality of speech performance, only a few studies (Sample \& Michel, 2014) have directly explored how task repetition may influence links between the linguistic complexity, accuracy, and fluency of oral production. As the aim of task-based teaching is to achieve a balanced development in all CAF areas, this is a key issue to investigate further. Research on this topic seems particularly important among child learner populations, given that repetition is a prominent feature of language play, which is assumed to play a key role in the development of children's communicative competence (Moore, 2012).

Against this background, one aim of the present study was to contribute to the existing literature by examining the effects of repeating a task with the same content on linguistic complexity, accuracy, and fluency among child language learners. A second aim of our research was to help gain a better understanding of how repeating a task may impact links between various CAF dimensions during L2 performance. We focused on child language learners in the Chinese context, a so far unexplored learner population. 


\section{Theoretical Perspectives on Task Repetition}

In the field of task-based language teaching, task repetition has gained prominence through the work of Bygate (1996, 2001, 2018; Samuda \& Bygate, 2005). Bygate drew on Levelt's (1989) speech production model when formulating his initial hypotheses about the effects of task repetition on L2 oral performance. According to Levelt, speech production includes four interactive stages. Conceptualization, the first stage, entails the macro- and micro-planning of one's message, that is, planning of what one intends to convey. The outcome of conceptualization is a pre-verbal message. Formulation, the second stage in the model, involves the transformation of the pre-verbal message into linguistic form, relying on lexical, syntactic, and morpho-phonological encoding processes. During articulation, the third stage, phonological forms are activated, and articulatory gestures are retrieved to help produce the speech utterance. Monitoring, the final stage, occurs across all stages, ensuring that the evolving message is an accurate reflection of the speaker's meaning and is formulated and articulated as intended. For L1 speakers, formulation and articulation processes are largely automatic. For less advanced L2 speakers, on the other hand, formulation operations tend to pose greater demands on attentional resources, as L2 speakers at lower levels of proficiency possess a smaller L2 mental lexicon and have less sophisticated syntactic and morpho-phonological encoding skills. As a result, in L2 speech, more severe competition for attentional resources is expected to emerge, generating tradeoff effects in the amount of attention learners have available for conceptualizing and formulating their message.

Based on Levelt's (1989) model, Bygate $(1996,2001,2018)$ proposed that task repetition is likely to have the capacity to mitigate any trade-off effects that may emerge between conceptualization and formulation processes during L2 speech production. As Bygate (2001, p. 29) explains, "part of the work of conceptualization, formulation and articulation carried out on the first occasion" may be "kept in the learners' memory store and can be reused on the second occasion." This may release some of the learners' attentional capacity to dedicate to different aspects of their performance, especially formulation and articulation. This, in turn, is anticipated to manifest in positive changes in the syntactic complexity, accuracy, and/or fluency of L2 learners' performance.

This line of reasoning is also compatible with Skehan's Limited Capacity model, which, also draws on speech production models (Levelt, 1989; Kormos, 2006) to explain task effects. Skehan $(2009,2015)$ proposed that task features may impose distinct demands on conceptualization and formulation operations, resulting in "complexifying/pressuring" and "easing/focusing" influences with respect to different speech production stages. For example, conceptualization processes are anticipated to face extra demands if a task entails handling unfamiliar information. In contrast, formulation operations will come under more pressure when, for instance, the task calls for using diverse and sophisticated lexical items and lacks opportunities for online planning. Applying these ideas to task repetition, it would appear that repeating a task has the capacity to ease pressure on both the conceptualizer and formulator. When a task is repeated, lower conceptualization demands are expected because the speaker no longer needs to decide what to say, and decreased pressure on formulation may result from language being rehearsed in the first performance and from having increased cognitive resources available due to less attention being 
consumed by conceptualization. As a consequence, there will probably be decreased tradeoff effects among the various CAF measures (Sample \& Michel, 2014).

\section{Effects of Task Repetition on CAF}

Plough and Gass (1993) were the first to examine the impact of repeating a task, focusing on the incidence of negotiation of meaning. Bygate's (1996) oft-cited work, however, constitutes the first attempt to investigate the effects of task repetition on the quality of linguistic production. As part of a case study, Bygate asked an adult learner to repeat the same task three days after their first performance. The task entailed narrating a story based on a Tom and Jerry cartoon. He found that the learner produced more grammatically accurate and fewer inappropriate collocations, a wider range lexis and cohesive devices, and a greater number of self-corrections. In another early study of task repetition, Lynch and Maclean $(2000,2001)$ observed similar patterns. They also adopted a case study approach and observed adult learners' repeated task performance during what they referred to as a poster carousel activity. This task involved participants in preparing a poster based on various medical research papers in pairs and then describing the poster repeatedly to different learners who visited the poster presentation. Lynch and Maclean found that, through the repeated visits, students improved their use of pronunciation, grammar, and vocabulary.

Some early experimental studies also observed positive effects for task repetition. Gass et al. (1999) found that L2 Spanish learners narrating the same Mr. Bean video for the third time displayed more accurate production of estar (= to be) and greater lexical sophistication. Like Gass et al. (1999), Bygate's (2001) experimental research revealed a positive impact of task repetition on L2 production. In this study, one experimental group worked on narrative tasks, while the other experimental group carried out interview tasks over a ten-week treatment period. The effects of task repetition were determined by examining participants' posttest performance on the same version of the narrative and interview task they had performed on the pretest ten weeks earlier. The experiment revealed improved performance for fluency and syntactic complexity, but not for accuracy. Bygate and Samuda (2005), using the same database, uncovered further positive effects of task repetition in terms of elaboration, reflected in more extensive use of adverbials and more detailed descriptions of the characters' motives, attitudes, and intentions.

More recent studies of task repetition generated additional evidence that repeating the same task has a positive influence on adult L2 learners' oral performance. Researchers confirmed a possible advantage for task repetition in terms of fluency (Ahmadian \& Tavakoli, 2011; Lambert et al., 2017; Sheppard \& Ellis, 2018), accuracy (Ahmadian \& Tavakoli, 2011; Fukuta, 2016), syntactic complexity (Ahmadian \& Tavakoli, 2011; Sheppard \& Ellis, 2018), lexical complexity (Fukuta, 2016), and/or discourse complexity (Wang \& Chen, 2018). As in Bygate's (2001) research, however, studies that have considered various CAF dimensions (e.g., Fukuta, 2016; Sheppard \& Ellis, 2018) did not tend to find superior performance on all CAF measures examined during repeated performance (see, however, Ahmadian \& Tavakoli, 2011), and the nature of gains varied. For example, Fukuta (2016) observed significant positive effects of task repetition on accuracy but not syntactic complexity and fluency, whereas Sheppard and Ellis (2018) found that learners showed gains in syntactic complexity and fluency but not in accuracy. 
Turning to child populations, although some of the existing research has exclusively focused on procedural repetition (Pinter, 2005, 2007a, 2007b; Sample \& Michel, 2014; de Jong \& Tillman, 2018), several studies have looked into the impact of repeating a task with the same content on children's oral production. Van den Branden (1997) was among the first to observe children's repeated task performance. The participants were 11- and 12-year-old students of Dutch, who carried out a description task either twice (comparison group) or three times (experimental groups) as part of a task sequence. The experimental groups differed as to whether they worked on the task with a peer or the teacher during their first repeated performance. Van den Branden revealed that all three groups used a wider range of lexis during their last performance as compared to the first. Additionally, the two experimental groups produced more output and essential information, with the experimental group who was "pushed" by the teacher achieving greater gains. None of the groups, however, displayed a change in terms of syntactic complexity or accuracy. Similar to Van den Branden's findings, Kim et al. (2018) observed positive effects for repeating a task in terms of lexical complexity among Korean middle school students of English. In particular, the researchers found that task repetition led to more extensive use of less familiar, less frequent, and late-acquired words.

Two task repetition studies of children, Kim and Tracy-Ventura (2013) and Thai and Boers (2016), are particularly relevant to the present research, given that both studies, like this experiment, examined the impact of repeating the same task on all three CAF dimensions. Kim and Tracy-Ventura (2013) used a pretest-posttest-delayed posttest design to compare the effects of exact and procedural task repetition on Korean middle school students' linguistic performance. During the treatment, the participants carried out three collaborative narrative tasks with either the same or different content. The testing tasks took the form of monologic narratives. When comparing learners' output across the testing sessions, the researchers found that exact task repetition promoted the use of task-induced linguistic features but did not benefit the complexity and fluency of learners' performance. Notably, this study differed from previous research in that it gauged the effects of task repetition on an assessment task that was distinct from the treatment tasks. Thai and Boers (2016) adopted a research design more aligned with that of this study, comparing learners' first and third performance on the same task. The participants were 15- to 16-year-old Vietnamese high-school students learning English. One experimental group repeated the same task (i.e., giving a talk) under the same conditions, whereas the other experimental group performed the task repeatedly under increasing time pressure. Task repetition led to superior fluency for both groups, but the increase in fluency was less marked for the exact task repetition group. Interestingly, exact task repetition resulted in improved performance also in terms of complexity and accuracy.

To sum up, similar to the results observed for adult populations, task repetition seems to have beneficial effects on the oral performance of children. The results, however, are mixed as to what area of linguistic performance (e.g., linguistic complexity, accuracy, and/or fluency) is facilitated through task repetition. Further research is needed to clarify this relationship; studies investigating all CAF dimensions are especially warranted to get a fuller picture of how task repetition affects the linguistic performance of child second language learners. 


\section{Task Repetition and Trade-Off Effects}

Another issue that needs further exploration is how repeating a task affects the relationships between various CAF measures. As discussed earlier, one possible benefit of task repetition might be that it decreases trade-off effects among different dimensions of linguistic performance, thereby promoting balanced development in various CAF domains (Skehan, 2009). To the best of our knowledge, only Sample and Michel (2014) have directly investigated whether task repetition, operationalized as procedural repetition, indeed has the capacity to influence links between various CAF measures. The participants were six children with a mean age of 9.5. They performed three spot-the-difference tasks, involving slightly different pictures, within a three-week period. As expected, participants displayed diminished trade-off effects when they engaged in repeated performance. The researchers observed significant negative correlations between accuracy and syntactic complexity during children's first and second performances and between fluency and lexical complexity on the second occasion they carried out the task. On the other hand, no significant negative correlations were identified when learners repeated the task for the third time. As the authors acknowledge, these results, given the small sample size, are exploratory and need to be confirmed in further research.

\section{Research Questions}

Against this background, we formed the following research questions:

1. What are the effects of task repetition on the syntactic complexity, accuracy and fluency of children's performance?

2. To what extent does task repetition influence the relationships between the syntactic complexity, accuracy, and fluency of children's task performance?

\section{Methodology}

\section{Design}

The present study adopted a within subject-design with each participant completing an oral storytelling task three times. The independent variable was task repetition, which was operationalized as the repetition of the same task type with the same content three times. The dependent variables were participants' linguistic complexity, accuracy, and fluency during the task performances.

\section{Participants}

The participants were 40 Chinese children learning English as a foreign language (EFL). They were all aged 11-12 years. Eighteen of the children were female, and 22 were male. The first language of the participants was Mandarin Chinese. They had all learned English for at least 5-6 years in their regular English classes as part of the state school curriculum, which provides learners with mainly form-focused instruction. In addition, they also took part in private language lessons at a language institute, the context where the 
current study was conducted. In this setting, the instruction was more communicativelyoriented. The proficiency level of the children was at A2 according to the Common European Framework of Reference for Languages (CEFR), as determined by their performance on a practice version of the A2 Flyers Cambridge English Young Learners test. Informed consent was obtained from both children and parents prior to the study.

\section{The Story-Telling Task}

The storytelling task was adopted from the speaking section of the A2 Flyers Cambridge English test designed for child English language learners. The task consisted of five pictures depicting a story about a boy and his father buying a TV and the process of taking it home. After purchasing the TV in the shop, an accident happens while the boy and his father are carrying the box with the TV into their house. The boy stumbles on the front door stairs, and the box drops to the ground. When the family opens the box, they are happy to find that the $\mathrm{TV}$ is not broken.

This storytelling was considered appropriate for the experiment for several reasons. First, storytelling is a classic classroom task (Skehan, 2018), often used by teachers in a variety of instructed contexts. This task type was also familiar to the participating children. Second, storytelling gives learners the opportunity to use language creatively, while eliciting a range of syntactic structures and cohesive devices (Papp, 2018).

No time limit was specified for task completion, given that lack of sufficient time to carry out the task might have negatively influenced learners' performance due to the limited visuo-spatial consciousness of children (Papp, 2018).

\section{Procedure}

Prior to completing the storytelling task, the children engaged in a pre-task activity. As part of the pre-task, they were asked to consider the story and match some key phrases to the pictures. In this way, the children had a chance to activate key vocabulary relevant to task completion as well as get familiar with the storyline. This pre-task phase lasted 10 minutes. Then, the children were asked to retell the story three times. They were able to see the pictures during task performance but had no access to the pre-task activity sheet. Each narration lasted about 1-3 minutes. The children were offered a short break of 5 minutes between the retellings. The performances of the students were captured through audiorecording.

\section{Data Analysis Procedures}

The recordings of participants' full task performances were transcribed and coded for measures of syntactic complexity, accuracy, and fluency by the first author. Once the data had been transcribed, the data were segmented into clauses and Analysis of Speech-units (AS-units, Foster et al., 2000). An AS-unit is defined as a "single speaker's utterance consisting of an independent clause or subclausal unit, together with any subordinate clause(s) associated with it" (Foster et al. 2000, p. 365).

To capture the multidimensional nature of syntactic complexity (Norris \& Ortega, 2009), we obtained measures of overall complexity, subordination complexity, and phrasal 
complexity. Overall complexity was computed by dividing the number of words in each sample by the number of AS-units (words per AS-unit). We obtained an index of subordination complexity by calculating the proportion of clauses to AS-units (clauses per AS-unit). Phrasal complexity was measured by dividing the number of words uttered in each performance by the number of clauses (words per clause) (Norris \& Ortega, 2009).

We used two global measures to gauge accuracy. We calculated the number of errors per 100 words (errors per 100 words) for all task performances. When identifying errors, we considered lexical and grammatical errors but ignored errors in pronunciation. The error ratios were calculated based on pruned speech, excluding false starts and repetitions. In addition, we computed a weighted clause ratio (WCR) for each speech sample (Foster \& Wigglesworth, 2016). Obtaining WCR for the performances involved three steps. First, clauses were classified into three levels: level 1 clauses, which contained few errors without impacting on communication; level 2 clauses, which had errors with some impact communication; and level 3 clauses, which included errors that had considerable impact on meaning. Second, we assigned relative scores to the various levels. Scores of 0.8, 0.5 and 0.1 were awarded to clauses classified as level 1, 2, and 3 respectively. Finally, for each task performance, the sum of the resulting values was divided by the number of clauses in the speech sample.

To measure fluency, we obtained indices of repair and breakdown fluency (Skehan, 2003). Repair fluency, the frequency with which false starts, repetitions, and selfcorrections occur in speech, was assessed by calculating the proportion of false starts, repetitions and self-corrections per 100 words. Breakdown fluency, a construct associated with pausing behaviour, was operationalized as the frequency of filled pauses (e.g., uhms, uhs) per 100 words.

The first author coded all speech samples. To check the reliability of the coding, we randomly selected eight participants, and their performances were additionally coded by a research assistant. Inter-coder agreement was found to be high for all coding categories (AS-unit: 100\%; clause: 100\%; errors: 93\%; WCR: 100\%; false starts: 95\%; repetitions: 95\%; self-corrections: $96 \%$; filled pauses:100\%). Table 1 provides a summary of the measures employed.

Table 1

Measures of syntactic complexity, accuracy, and fluency

\begin{tabular}{ll}
\hline \multicolumn{1}{c}{ Variable } & \multicolumn{1}{c}{ Measurement } \\
\hline Syntactic complexity & Words per AS-unit \\
& Clauses per AS-unit \\
& Words per clause \\
\hline Accuracy & Errors per 100 words \\
& Weighted Clause Ratio \\
\hline Fluency & False starts per 100 words \\
& Repetitions per 100 words \\
& Self-corrections per 100 words \\
& Filled pauses per 100 words \\
\hline
\end{tabular}




\section{Statistical Analyses}

The data were analyzed with SPSS 26.0. As some of the distributions did not meet the normality assumption, we computed medians and interquartile ranges to describe the data and employed non-parametric inferential tests to assess the significance of the results. To address research question 1, we carried out a series of Wilcoxon Signed Ranks tests to compare the learners' performance during the first and third story retelling in terms of the syntactic complexity, accuracy, and fluency measures. An index of $r$ was computed to assess effect size for the analyses. To investigate research question 4, we conducted Spearman correlational analyses between the various syntactic complexity, accuracy, and fluency indices for the first and third task performances separately. Following Plonsky and Oswald (2014), $r$ values of $.25, .40$, and .60 were interpreted as small, medium, and large, respectively. The level of significance was set at .05 .

\section{Results}

\section{The Effects of Task Repetition on Linguistic Performance}

In our first research question, we asked the extent to which task repetition affected the syntactic complexity, accuracy, and fluency of children's performance. Table 2 gives the results for the descriptive statistics for the various linguistic indices and the results of the Wilcoxon Signed Ranks tests. While repeating the task did not appear to have much influence on the syntactic complexity of children's production, it seemed to have a positive impact on their accuracy and fluency. As shown in Table 2, the Wilcoxon Signed Ranks tests confirmed that children produced significantly more accurate and fluent speech when they repeated the task for the third time, as compared to their first performance. More specifically, they produced a significantly smaller number of errors, filled pauses, false starts, repetitions, and self-corrections during the third retelling than the first. The effect size for number of errors and self-corrections was found to be small, for false starts it fell in the medium range, and for filled pauses and repetitions it was large. 
Table 2

Descriptive statistics for CAF measures and results of Wilcoxon Signed Ranks tests $(N=40)$

\begin{tabular}{|c|c|c|c|c|c|c|c|c|c|c|c|}
\hline \multirow{2}{*}{ Measures } & \multicolumn{4}{|c|}{ Time1 } & \multicolumn{4}{|c|}{ Time 3} & \multicolumn{3}{|c|}{ Wilcoxon Signed Ranks } \\
\hline & Median & IQR & $\begin{array}{c}95 \% \\
\text { CI } \\
\text { Lower }\end{array}$ & $\begin{array}{c}95 \% \\
\text { CI } \\
\text { Upper }\end{array}$ & Median & IQR & $\begin{array}{c}95 \% \\
\text { CI } \\
\text { Lower }\end{array}$ & $\begin{array}{c}95 \% \\
\text { CI } \\
\text { Upper }\end{array}$ & $\mathrm{Z}$ & $\mathrm{p}$ & $\mathrm{r}$ \\
\hline \multicolumn{12}{|l|}{ Syntactic complexity } \\
\hline Words per AS-unit & 8.13 & 2.33 & 7.62 & 8.86 & 8.47 & 2.86 & 7.67 & 9.07 & -.65 & .52 & -.10 \\
\hline Clauses per AS-unit & 1.33 & .41 & 1.21 & 1.50 & 1.33 & .37 & 1.27 & 1.50 & -1.34 & .18 & -.21 \\
\hline Words per clause & 6.04 & 1.22 & 5.60 & 6.33 & 6.06 & .86 & 5.81 & 6.29 & -.18 & .86 & -.03 \\
\hline \multicolumn{12}{|l|}{ Accuracy } \\
\hline Errors per 100 words & .09 & .07 & .07 & .11 & .07 & .06 & .05 & .09 & -2.34 & .02 & -.37 \\
\hline Weighted Clause Ratio & .80 & .39 & .66 & .86 & .80 & .38 & .68 & .91 & -1.40 & .16 & -.22 \\
\hline \multicolumn{12}{|l|}{ Fluency } \\
\hline False starts/100 words & .02 & .04 & .01 & .03 & $<.01$ & .02 & $<.01$ & .01 & -3.37 & $<.01$ & -.53 \\
\hline Repetitions/100 words & .07 & .09 & .03 & .09 & .02 & .07 & .01 & .05 & -3.80 & $<.01$ & -.60 \\
\hline Self-corrections/100 & .03 & .04 & .02 & .04 & .02 & .03 & .01 & .03 & -2.08 & .04 & \\
\hline words & & & & & & & & & & & -.33 \\
\hline Filled pauses/100 words & 12.35 & 12.77 & 9.26 & 16.69 & 6.31 & 6.26 & 4.80 & 8.21 & -4.87 & $<.01$ & -.77 \\
\hline
\end{tabular}




\section{The Influence of Task Repetition on the Relationships Between Linguistic Performance Measures}

Our second research question was concerned with the extent to which task repetition influences the relationships between syntactic complexity, accuracy, and fluency during children's task performance. Tables 3 and 4 provide the results of the Spearman correlational analyses of the Time 1 and Time 3 performances respectively.

The analyses yielded similar patterns for the relationships between the various subconstructs of the syntactic complexity, accuracy, and fluency measures. Medium to strong correlations were found between the different syntactic complexity indices, the only exception being a lack of significant link between the indices of phrasal and subordination complexity. The two accuracy measures were also found to have a strong correlation. Similar, the analyses yielded medium-size links between most fluency indices, with the exception between the frequency of false starts and frequency of self-corrections (both Time 1 and Time 3 ) and filled pauses (only Time 3).

Turning to the links between the main CAF constructs, we observed some notable differences between the Time 1 and Time 3 performances. At Time 1, we found that weighted clause ratio had small-size negative correlations with overall and subordination complexity. In addition, the analyses generated a small-size negative link between the incidence of filled pauses and overall complexity. A small-size negative relationship between frequency of repetitions and number of errors also emerged (more repetitions indicate lower fluency). At Time 3, while the significant link between number of errors and repetitions was sustained, the rest of the correlations were smaller in size and did not reach significance. These results mean that, at both Times 1 and 3, participants who produced more fluent speech tended to be less accurate. However, the patterns for Time 1 and Time 3 differed for the rest of the relationships. During their first performance, if children produced more syntactically complex speech, they were less accurate or fluent. By the time of their third performance, however, the trade-off effects between syntactic complexity and accuracy and between syntactic complexity and fluency decreased and did not reach significance. 
Table 3

Correlations between CAF measures at Time $1(N=40)$

\begin{tabular}{|c|c|c|c|c|c|c|c|c|}
\hline & \multicolumn{2}{|c|}{$\begin{array}{c}\text { Syntactic } \\
\text { complexity }\end{array}$} & \multicolumn{2}{|c|}{ Accuracy } & \multicolumn{4}{|c|}{ Fluency } \\
\hline & $\begin{array}{c}\text { Clauses } \\
\text { /AS- } \\
\text { unit }\end{array}$ & $\begin{array}{l}\text { Words/ } \\
\text { clause }\end{array}$ & $\begin{array}{c}\text { Error } \\
\text { number }\end{array}$ & WCR & $\begin{array}{l}\text { False } \\
\text { starts }\end{array}$ & $\begin{array}{l}\text { Repeti- } \\
\text { tions }\end{array}$ & $\begin{array}{c}\text { Self- } \\
\text { correct. }\end{array}$ & $\begin{array}{l}\text { Filled } \\
\text { pauses }\end{array}$ \\
\hline \multicolumn{9}{|c|}{ Syntactic complexity } \\
\hline Words/ rho & $.76^{* *}$ & $.46^{* *}$ & .03 & $-.33^{*}$ & -.09 & -.08 & -.08 & $-.36^{*}$ \\
\hline AS-unit $p$ & $<.01$ & $<.01$ & .87 & .04 & .59 & .62 & .63 & .02 \\
\hline Clauses/ rho & & -0.13 & .08 & $-.36^{*}$ & .03 & -.13 & -.26 & -.18 \\
\hline AS-unit $p$ & & .43 & .63 & .02 & .85 & .43 & .10 & .26 \\
\hline Words rho & & & -.04 & .05 & -.21 & .06 & .25 & -.18 \\
\hline /clause $\quad p$ & & & .82 & .74 & .20 & .72 & .12 & .27 \\
\hline \multicolumn{9}{|l|}{ Accuracy } \\
\hline Error & & & & $-.57^{* *}$ & .23 & $.39^{*}$ & .09 & .03 \\
\hline number $p$ & & & & $<.01$ & .15 & .01 & .57 & .86 \\
\hline WCR & & & & & -.01 & -.15 & .21 & .16 \\
\hline$p$ & & & & & .95 & .35 & .20 & .33 \\
\hline \multicolumn{9}{|l|}{ Fluency } \\
\hline False rho & & & & & & $.37^{*}$ & .27 & $.38^{*}$ \\
\hline starts & & & & & & .02 & .09 & .01 \\
\hline Repeti- rho & & & & & & & $.41^{* *}$ & $.44^{* *}$ \\
\hline tions & & & & & & & 0.01 & $<.01$ \\
\hline Self- & & & & & & & & $.36^{*}$ \\
\hline correct. $p$ & & & & & & & & .02 \\
\hline
\end{tabular}


Table 4

Correlations between CAF measures at Time $3(N=40)$

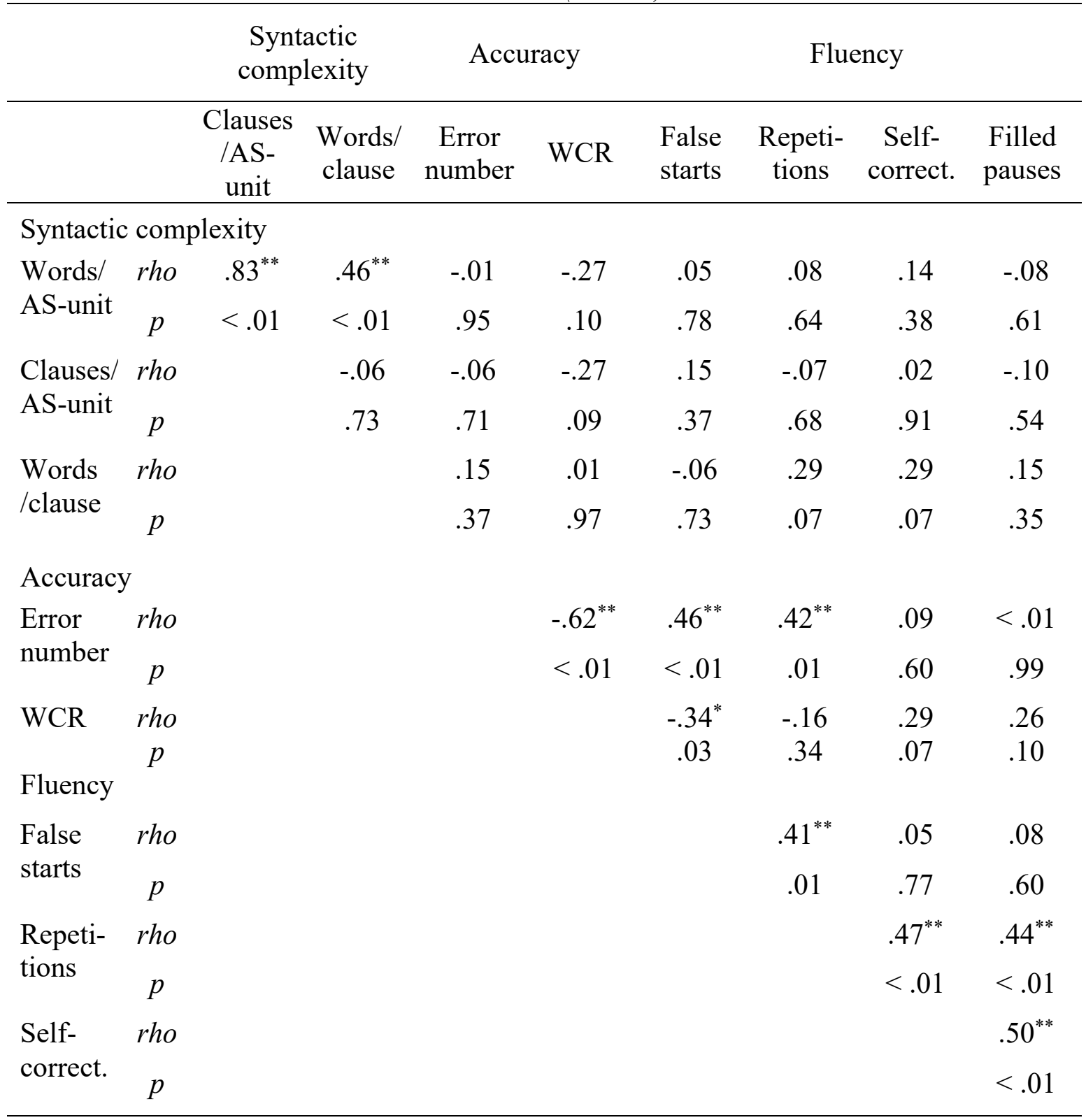

\section{Discussion}

Our first research question was concerned with the effects of task repetition on the syntactic complexity, accuracy, and fluency of childrens' linguistic performance. We found that children showed greater accuracy and fluency when performing the same story-telling task for the third time. In particular, they produced fewer errors, filled pauses, false starts, repetitions and self-corrections during their third as compared to their first task performance. Overall, the effect sizes for the fluency measures were found to be larger than for the accuracy indices. Task repetition, however, did not lead to more syntactically complex speech. These results are well aligned with Bygate's $(1996,2001,2018)$ 
hypothesis that, when repeating a task, learners will have greater attentional capacity to allocate to various aspects of their linguistic output, as the relevant conceptualization and formulation processes have already been rehearsed during their first performance. Our findings are also consistent with those of other studies involving child populations, providing further evidence that task repetition has a positive impact not only on adult but also child language learners' linguistic performance.

Similar to most studies, however, not all areas of task performance were promoted in the current study. The positive results obtained for fluency are well in line with the results of many previous task repetition studies (e.g., Ahmadian \& Tavakoli, 2011; Bygate, 2001; Sheppard \& Ellis, 2018; Thai \& Boers, 2016; see, however, Fukuta, 2016). There are several possible reasons

for the beneficial effects observed. First, learners' familiarity with the topic during repeated performance probably eased pressure on conceptualization processes (Bygate, 1996; Skehan, 2009), enabling participants to make faster decisions about what to say. On the other hand, there were likely lower demands on formulation processes as well, given that the children had already rehearsed the language to be used in earlier performances (Bygate, 1996; Skehan, 2009). This might have speeded up lexical and morphosyntactic encoding processes.

Turning to the results for accuracy and complexity, our findings mirror the findings of some previous research who also found a facilitative impact of task repetition on accuracy but not complexity (Fukuta, 2016), but run counter to those who observed positive effects for complexity but not accuracy (Bygate, 2001; Sheppard \& Ellis, 2018) or for both accuracy and complexity (Ahmadian \& Tavakoli, 2011; Thai \& Boers, 2016). Notably, except for Thai and Boers, most exact task repetition studies employed narrative tasks as elicitation devices. A common feature of the narratives used in Fukuta's and our research was that both experiments used picture narrative tasks with ordered cartoon strips to elicit the speech performances. On the other hand, in Sheppard and Ellis's study participants had to tell a story based on jumbled pictures, whereas in Bygate's and Ahmadian and Tavakoli's work participants were asked to engage in video retellings. Probably, when learners had additional attentional resources during repeated performance, the need to depict a story based on unordered cartoon strips or a previously watched video prompted participants to provide more explicit links between the events in their retellings, given that the relationships between events were less obvious to the listener, as compared to when the learners were presented with ordered pictures. In turn, this might have induced learners to challenge themselves to a greater extent and experiment more with sophisticated language use, resulting in greater syntactic complexity (Robinson, 2001). By contrast, in Fukuta's and the current study, the freed-up attentional capacity was likely channelled towards accuracy rather than complexity during repeated performance, given that the nature of the task called for less complexification in terms of language, due to lower demands on learners to link events explicitly.

In our second research question, we investigated the extent to which task repetition influenced the relationships between the syntactic complexity, accuracy, and fluency of children's speech production. Our results revealed that, when participants carried out the task for the third time, most trade-off effects that we had observed during the first performance had decreased by the time of their third retelling of the picture story. More specifically, while some significant negative correlations were found between accuracy 
(weighted clause ratio) and syntactic complexity (subordination, overall), fluency (filled pauses) and syntactic complexity (overall), and fluency (number of repetitions) and accuracy at Time 1, the negative correlation was only sustained between fluency and accuracy at Time 3. Simply put, on both occasions, children seem to have prioritized either accuracy or fluency. However, any trade-off effects involving syntactic complexity had decreased from the first retelling to the third. If children produced more accurate or fluent speech during their first retelling, they were likely to use less syntactically complex language. Alternatively, if they displayed lower accuracy or fluency, they tended to show increased syntactic complexity. By Time 3, however, only decreased, non-significant tradeoff effects were observed between the measures of syntactic complexity and those of accuracy and fluency.

These results are consistent with predictions derived from Skehan's $(1998,2009)$ Limited Capacity model. As discussed earlier, having rehearsed the task might have eased pressure on children's conceptualization and/or formulation processes, resulting in increased cognitive resources available during subsequent performances. The enhanced attentional capacity, then, probably enabled children to increase their accuracy or fluency while maintaining a similar level of syntactic complexity, given that task repetition, overall, was found to have a positive impact on accuracy and fluency but not on syntactic complexity.

Our findings confirm the trends observed in Sample and Michel's (2014) exploratory study. Like the present study, Sample and Michel found that any trade-off effects they had observed during participant's first task performance were not maintained when they repeated the task for the third time. Importantly, however, the children in Sample and Michel's research did not engage in exact task repetition, thus our study extended their findings to this procedure. Also, our results are less exploratory in nature given the considerably larger number of participating students.

\section{Limitations and Directions for Future Research}

Before drawing our conclusions, we turn to a discussion of the limitations of the study and some possible future directions. One weakness of the current research is that we did not include a measure of speed fluency and did not calculate the frequency of silent pauses. This decreases the comparability of our findings to those of some previous studies. Future studies of task repetition would also benefit from including more specific linguistic measures that are relevant to task completion (e.g., use of verb tenses and temporal connectives in narratives). A further shortcoming concerns our exclusive focus on Time and Time 3 performances, in a follow-up study it would be worthwhile to compare the patterns across all three performances. Another limitation of the present experiment lies in its one-shot design; it provides no information about the long-term effects of repeating tasks with the same content. In future research, it would be worthwhile to investigate the longitudinal impact of task repetition on children's speech development. Finally, the present study did not consider individual differences among learners, which might have moderated the results. Children's performance could have been influenced by a wide variety of factors, including working memory capacity, aptitude, motivation, and anxiety. Further research is warranted to explore how these factors and other individual difference variables may interact with task repetition. 


\section{Conclusion}

This study had two main aims. First, it intended to expand on the existing literature by investigating the impact of exact task repetition on the linguistic complexity, accuracy, and fluency of children's speech performance. We found that repeating a task had positive effects on learners' fluency and accuracy, but not syntactic complexity. We attributed the lack of beneficial impact for syntactic complexity to the nature of ordered picture narratives, which might encourage greater focus on accuracy. The second aim of our research was to obtain an understanding of how task repetition may influence relationships between different CAF dimensions. We observed that trade-off effects that had emerged during learners' first performance had not been sustained during their third retelling. Taken together, the present research confirms previous research findings that exact task repetition is a useful pedagogical tool for L2 teachers of children, as it leads to improved speech performance. In addition, our results extend current knowledge by demonstrating that exact task repetition can help achieve balanced development in all CAF areas, which has been proposed as the ultimate aim of developing oral skills in L2 instructed contexts (Skehan, 1998).

Correspondence should be addressed to Bo Sun.

Email: bo.sun.18@alumni.ucl.ac.uk

\section{References}

Ahmadian, M. J., \& Tavakoli, M. (2011). The effects of simultaneous use of careful online planning and task repetition on accuracy, complexity, and fluency in EFL learners' oral production. Language Teaching Research, 15(1), 35-59.

Bygate, M. (1996). Effects of task repetition: Appraising the developing language of learners. In J. Willis, \& D. Willis (Eds.), Challenge and change in language teaching (pp. 136-146). Heinemann.

Bygate, M. (2009). Effects of task repetition on the structure and control of oral language. In K. Van den Branden, M. Bygate, \& J. Norris (Eds.), Task-based language teaching: A reader (pp. 249-274). John Benjamins Publishing Company.

Bygate, M. (2018). Introduction. In M. Bygate (Ed.), Learning language through task repetition (pp. 1-25). John Benjamins Publishing Company.

Bygate, M., \& Samuda, V. (2005). Integrative planning and the use of task repetition. In R. Ellis (Ed.), Planning and task performance in a second language (pp. 37-74). John Benjamins Publishing Company.

Bygate, M. (2001). Effects of task repetition on the structure and control of oral language. In M. Bygate, P. Skehan, \& M. Swain (Eds.), Researching pedagogic tasks: second language learning, teaching and testing (pp. 23-48). Longman.

de Jong, N., \& Tillman, P. (2018). Grammatical structures and oral fluency in immediate task repetition: Trigrams across repeated performances. In M. Bygate (Ed.), Learning language through task repetition (pp. 43-73). John Benjamins Publishing Company.

Ferrari, S. (2012). A longitudinal study of complexity, accuracy and fluency variation in second language development. In A. Housen, F. Kuiken, \& I. Vedder (Eds.), Dimensions of L2 performance and proficiency: Complexity, accuracy and fluency in SLA (pp. 277-297). John Benjamins Publishing Company. 
Foster, P., Tonkyn, A., \& Wigglesworth, G. (2000). Measuring spoken language: A unit for all reasons. Applied Linguistics, 21(3), 354-375.

Foster, P., \& Wigglesworth, G. (2016). Capturing accuracy in second language performance: The case for a weighted clause ratio. Annual Review of Applied Linguistics, 36, 98-116.

Gass, S. M., Mackey, A., Alvarez-Torres, M. J., \& Fernândez-Garcîa, M. (1999). The effects of task repetition on linguistic output. Language Learning, 49(4), 549-581.

Fukuta, J. (2016). Effects of task repetition on learners' attention orientation in L2 oral production. Language Teaching Research, 20(3), 321-340.

Kim, Y., \& Tracy-Ventura, N. (2013). The role of task repetition in L2 performance development: What needs to be repeated during task-based interaction? System, 41(3), 829-840.

Kormos, J. (2006). Speech production and second language acquisition. Lawrence Erlbaum Associates.

Lambert, C., Kormos, J., \& Minn, D. (2017). Task repetition and second language speech processing. Studies in Second Language Acquisition, 39, 167-196.

Levelt, W. J. M. (1989). Speaking: From intention to articulation. MIT Press.

Long, M. H., \& Robinson, P. (1998). Focus on form: Theory, research, and practice. In C. Doughty, \& J. Williams (Eds.), Focus on form in classroom second language acquisition (pp. 15-41). Cambridge University Press.

Lynch, T., \& Maclean, J. (2000). Exploring the benefits of task repetition and recycling for classroom language learning. Language Teaching Research, 4(3), 221-250.

Lynch, T., \& Maclean, J. (2001). A case of exercising: Effects of immediate task repetition on learners' performance. In M. Bygate, P. Skehan, \& M. Swain (Eds.), Researching pedagogic tasks: Second language learning teaching and testing (pp. 141-162). Pearson Education.

Mackey, A., Kanganas, A. P., \& Oliver, R. (2007). Task familiarity and interactional feedback in child ESL classrooms. TESOL Quarterly, 41(2), 285-312.

Moore, L. C. (2012). Language socialization and repetition. In A. Duranti, E. Ochs, \& B. Schieffelin (Eds.), The handbook of language socialization (pp. 209-226). Blackwell Publishing Limited.

Norris, J. M., \& Ortega, L. (2009). Towards an organic approach to investigating CAF in instructed SLA: The case of complexity. Applied Linguistics, 30(4), 555-578.

Papp, S. (2018). Context Validity of speaking tests of English for young learners. In N. Saville, \& C. J. Weir (Eds.), Examining young learners: research and practice in assessing the English of school-age learners (pp. 341-381). Cambridge University Press.

Plonsky, L., \& Oswald, F. L. (2014). How big is "big"? Interpreting effect sizes in L2 research. Language Learning, 64(4), 878-912.

Pinter, A. (2005). Task repetition with 10-year-old children. In C. Edwards, \& J. Willis (Eds.), Teachers exploring tasks in English language teaching (pp. 113-126). Macmillan.

Pinter, A. (2007a). Some benefits of peer-peer interaction: 10-year-old children practising with a communication task. Language Teaching Research, 11(2), 189-207. 
Pinter, A. (2007b). What children say: Benefits of task repetition. In K. Van den Branden., K. Van Gorp., \& M. Verhelst (Eds.), Tasks in action: Task-based language education from a classroom-based perspective (pp. 131-158). Cambridge Scholars Publishing.

Robinson, P. (2001). Task complexity, cognitive resources, and syllabus design: A triadic framework for investigating task influences on SLA. In Robinson, P. (Ed.), Cognition and second language instruction (pp. 287-318). Cambridge University Press.

Sample, E., \& Michel, M. (2014). An exploratory study into trade-off effects of complexity, accuracy and fluency in young learners' oral task repetition. TESL Canada Journal, 31(8), 23-46.

Samuda, V., \& Bygate, M. (2008). Tasks in second language learning. Palgrave MacMillan.

Sheppard, C., \& Ellis, R. (2018). The effects of awareness-raising through stimulated recall on the repeated performance of the same task and on a new task of the same type. In M. Bygate (Ed.), Learning language through task repetition (pp. 171-192). John Benjamins Publishing Company.

Skehan, P. (1998). A cognitive approach to language learning. Oxford University Press.

Skehan, P. (2003). Task based instruction. Language Teaching, 36(1), 1-14.

Skehan, P. (2009). Modelling second language performance: Integrating complexity, accuracy, fluency, and lexis. Applied linguistics, 30(4), 510-532.

Skehan, P. (2015). Limited attentional capacity and cognition: Two hypotheses regarding second language performance on tasks. In M. Bygate (Ed.), Domains and directions in the development of TBLT: A decade of plenaries from the international conference (pp. 123-155). Amsterdam/Philadelphia: John Benjamins Publishing Company.

Skehan, P. (2018). Second language task-based performance: Theory, research, and assessment. Routledge

Thai, C., \& Boers, F. (2016). Repeating a monologue under increasing time pressure: effects on fluency, complexity, and accuracy. TESOL Quarterly, 50(2), 369-393.

Van den Branden, K. (1997). Effects of negotiation on language learners' output. Language Learning, 47(4), 589-636.

Wang, Z., \& Chen, G. (2018). Discourse performance in L2 task repetition. In M. Bygate (Ed.), Learning language through task repetition (pp. 97-116). John Benjamins Publishing Company. 